\title{
Interactions of Cholesterol with Cyclodextrins in Aqueous Solution
}

\author{
Juziro NishiJo, * Shiho Moriyama, and Sachiko Shiota \\ Kobe Pharmaceutical University; Motoyama-kitamachi, Higashinada-ku, Kobe 658-8558, Japan. \\ Received May 30, 2003; accepted August 26, 2003
}

\begin{abstract}
The interaction of cholesterol with several cyclodextrins (CDs) was investigated in water using solubility method. It was found that heptakis (2,6-di- $O$-methyl)- $\beta$-CD (DOM- $\beta$-CD) forms two types of soluble complex, with molar ratios of $1: 1$ and $1: 2$ (cholesterol:DOM- $\beta$-CD), and neither a soluble nor insoluble complex is formed between cholesterol and $\alpha-\mathrm{CD}, \beta-\mathrm{CD}$, and $\gamma-\mathrm{CD}$, although a minor soluble complex formation was observed between cholesterol and 2-hydroxylpropyl- $\beta$-CD. The thermodynamic parameters for $1: 1$ and $1: 2 \mathrm{com}-$ plex formation of cholesterol with DOM- $\beta$-CD obtained from the changes in $K$ with temperature are as follows: $\Delta G_{1: 1}^{\circ}=-11.6 \mathrm{~kJ} / \mathrm{mol}^{\circ}$ at $25^{\circ} \mathrm{C}\left(K_{1: 1}=1.09 \times 10^{2} \mathrm{M}^{-1}\right) ; \Delta H_{1: 1}^{\circ}=-3.38 \mathrm{~kJ} / \mathrm{mol} ; T \Delta S_{1: 1}^{\circ}=8.25 \mathrm{~kJ} / \mathrm{mol}^{\circ} \Delta G_{1: 2}^{\circ}=-27.1$ $\mathrm{kJ} / \mathrm{mol}$ at $25^{\circ} \mathrm{C}\left(K_{1: 2}=5.68 \times 10^{4} \mathrm{M}^{-1}\right) ; \Delta H_{1: 2}^{\circ}=-3.96 \mathrm{~kJ} / \mathrm{mol}$; and $T \Delta S_{1: 2}^{\circ}=23.2 \mathrm{~kJ} / \mathrm{mol}$. The formation of the $1: 2$ complex occurred much more easily than that of the $1: 1$ complex. The driving force for $1: 1$ and $1: 2$ complex formation was considered to be mainly hydrophobic interaction. Also, based on the measurements of proton nuclear magnetic resonance spectra and studies with Corey-Pauling-Koltun atomic models, the probable structutures of the $1: 2$ complex were estimated.
\end{abstract} NMR

Key words cholesterol; 2,6 -di- $O$-methyl (DOM)- $\beta$-cyclodextrin; interaction; solubility method; thermodynamic parameter; ${ }^{1} \mathrm{H}$ -

Cholesterol exists in a buried form in phospholipids in the external brim of lipoprotein in plasma. ${ }^{1,2)}$ Cholesterol also exisits in a buried form in phospholipid bilayer in the biomembrane. ${ }^{1,2)}$ It is suggested that the interactions of cholesterol with phospholipids are based on the hydrophobic interaction. Therefore, it is presumed that cyclodextrins (CDs), cyclic oligosaccharides that have a hydrophobic cavity, interact with cholesterol to form inclusion complexes in aqueous solution. Several studies on the interactions of CDs with cholesterol have been reported. For example, intravenous administration of 2 -hydroxypropyl- $\beta$-CD (HP- $\beta$-CD) in rats leads to a trasient decrease in plasma cholesterol levels. ${ }^{3)}$ This phenomenon is explained as follows: in blood, high cholesterol concentration is available due to the complex formation with $\mathrm{HP}-\beta-\mathrm{CD}$, and this complex can be transported rapidly from the intravascular to the extravascular compartment. In other studies, it has been reported that cholesterol can be extracted from both cell and monolayer membranes by CDs. ${ }^{2,4,5)}$ However, all studies concerning these interactions are qualitative and, to the best of our knowledge, no studies on the thermodynamic parameters of interaction of cholesterol with CDs in aqueous solution have been reported.

We therefore investigated the interactions of cholesterol with CDs in aqueous solution quantitatively using the solubility measurement now common in pharmaceutical field, measurement of proton nuclear magnetic resonance $\left({ }^{1} \mathrm{H}\right.$ NMR), and Corey-Pauling-Koltun (CPK) atomic models. As $\mathrm{CDs}, \alpha-\mathrm{CD}, \beta-\mathrm{CD}, \mathrm{HP}-\beta-\mathrm{CD}, \gamma-\mathrm{CD}$, and heptakis $(2,6-\mathrm{di}-O-$ methyl)- $\beta$-CD (DOM- $\beta$-CD) were used. $\alpha$-CD, $\beta$-CD, and $\gamma$ $\mathrm{CD}$ contain six, seven, and eight glucopyranose units, respectively. The structure of the CDs is that of a truncated cone with average cavity diameters of $0.57,0.78$ and $0.95 \mathrm{~nm}$ for $\alpha-\mathrm{CD}, \beta-\mathrm{CD}$, and $\gamma-\mathrm{CD}$, respectively. These three CDs are less hydrophobic, and HP- $\beta$-CD with the same cavity diameter as $\beta-\mathrm{CD}$ is even less hydrophobic. On the other hand, DOM- $\beta$-CD has a deeper cavity and is more hydrophobic than $\beta$-CD.

\section{Experimental}

Materials $\alpha-\mathrm{CD}, \beta-\mathrm{CD}, \gamma-\mathrm{CD}$, and DOM- $\beta$-CD, purchased from Nacalai Tesque Co. (Kyoto, Japan) were used after recrystallization from water. HP- $\beta$-CD was purchased from Aldrich Chemical Company, Inc. The average degree of the 2-hydroxylpropyl group per $\beta$-CD was 5.6. The CDs were dried for $12 \mathrm{~h}$ at $110^{\circ} \mathrm{C}$ in a vacuum before use. Cholesterol purchased from Sigma (St. Louis, MO, U.S.A.) was used without further purification. The water purified with Milli-Q Labo $(>18 \mathrm{M} \Omega \cdot \mathrm{cm})$ was used throughout experiment.

Solubility Method (1): Solubility of Cholesterol First, the solubility of cholesterol in water was determined at $10,25,37$, and $45 \pm 0.05^{\circ} \mathrm{C}$. Excess cholesterol was added in L-type test tubes containing water and the test tubes were stoppered. The solutions containing excess cholesterol were shaken 100 times/min for $8 \mathrm{~d}$ to achieve the solubilitiy equilibrium. The solution was then filtered through a membrane filter $(0.22 \mu \mathrm{m}$, PVDF Membrane, IWAKI) (Tokyo, Japan) and the filtrate $(100.0 \mathrm{ml})$ was concentrated completely in rotary evaporater at $40{ }^{\circ} \mathrm{C}$ under reduced pressure. Then $2.0 \mathrm{ml}$ of $0.01 \mathrm{M} \mathrm{DOM}-\beta$-CD aqueous solution was added to solubilize the residue. The concentration of cholesterol in $2.0 \mathrm{ml}$ was determined by Free Cholesterol E-Test Wako supplied by Wako Pure Chemical Industries, Ltd. (Osaka, Japan). Color-producing reagent $(3.0 \mathrm{ml})$ was added to $0.10 \mathrm{ml}$ of the solubilized solution. Then the reaction mixture was heated for $5 \mathrm{~min}$ at $37^{\circ} \mathrm{C}$ and the absorbance at $600 \mathrm{~nm}$ was meaured using the calibration curve made in advance. Solibility of cholesterol in water was determined in 50fold dilutions of the solutions. It was confirmed that CDs do not affect the coloration of cholesterol using the Free Cholesterol E-Test Wako.

Solubility Method (2): Solubility of Cholesterol in the Presence of CD Aliquots $(7.0 \mathrm{ml})$ of $\mathrm{CD}$ aqueous solution of the appropriate concentration and excess cholesterol were placed in $20 \mathrm{ml}$ L-type test tubes and the tubes were sealed. The test tubes were kept at $10,25,37$ and $45 \pm 0.05^{\circ} \mathrm{C}$, respectively, with shaking, for 1 week until solubility equilibrium was achieved. Then the solution was filtered through the membrane described above and $3.0 \mathrm{ml}$ of color-producing reagent was added to $0.1 \mathrm{ml}$ of the filtrate. The solubility of cholesterol in the presence of $\mathrm{CD}$ was determined in the same way as described above, except for the dilution.

Fluorescence Spectra Fluorescence spectra were measured with a Shimadzu RF-503A fluorescence spectrophotometer at $25^{\circ} \mathrm{C}$.

${ }^{1}$ H-NMR Spectra ${ }^{1}$ H-NMR measurements were recorded on a Varian VXR-500 spectrometer with tetramethylsilane (TMS) as an external reference in deuterium oxide at $25^{\circ} \mathrm{C}$. Two-dimensional rotating frame nuclear Overhauser effect spectroscopy (ROESY) experiments were performed in the phase-sensitive mode using the State-Haberkorn method. A spinlock mixing pulse of $400 \mathrm{~ms}$ was used. 


\section{Results}

As preliminary experiments, the absorbances at $600 \mathrm{~nm}$ due to cholesterol solubilized in the presence of $1.0 \times 10^{-2} \mathrm{M}$ CDs at $37^{\circ} \mathrm{C}$ were measured according to Solubility Method (2) in the Experimental section. The results are shown in Table 1 . In the presence of $\alpha-\mathrm{CD}, \beta-\mathrm{CD}$, and $\gamma-\mathrm{CD}$, the absorbances were zero, suggesting that these CDs do not form soluble complexes with cholesterol in aqueous solution. Although only a slight increase in absorbance was observed in the presence of HP- $\beta$-CD, a remarkable increase in absorbance was observed in the presence of DOM- $\beta$-CD. These results suggest that DOM- $\beta$-CD has a strong ability to form soluble complex with cholesterol in aqueous solution, but HP- $\beta$-CD only a weak ability. Although soluble complex formations of cholesterol with $\alpha-\mathrm{CD}, \beta-\mathrm{CD}$, and $\gamma-\mathrm{CD}$ were not detected, insoluble complex formation might occur. Therefore, we investigated whether insoluble complexes between cholesterol and these CDs are formed in aqueous solution using 6-p-toluidinylnaphthalene-2-sulfonate (TNS). It has been reported that the fluorescence intensity of TNS is quenched in water, but increases markedly when CDs such as $\alpha-\mathrm{CD}, \beta-\mathrm{CD}$, and $\gamma-\mathrm{CD}$ are added to the aqueous solution. ${ }^{6,7)}$ The fluorescence intensity of TNS increases with increasing $\mathrm{CD}$ concentration. The filtrate $(5.0 \mathrm{ml})$ prepared in the presence of $\beta$-CD $\left(1.0 \times 10^{-2} \mathrm{M}\right)$ at $37^{\circ} \mathrm{C}$ according to Solubility Method (2) was added to TNS $1.0 \mathrm{ml}\left(1.0 \times 10^{-4} \mathrm{M}\right)$ and adjusted to a volume of $10.0 \mathrm{ml}$ with water. The fluorescence intensity of the test solution obtained was measured and compared with that of the control solution. The control solution contained the same concentration of $\beta-\mathrm{CD}$ as the test solution, but did not contain cholesterol. The results are shown in Fig. 1.

The fluorescence intensity of the test solution agreed with that of control. If an insoluble complex was formed between cholesterol and $\beta$-CD, the $\beta$-CD concentration in the test solution would decrease and the fluorescence intensity of the test solution would become less than that of the control solution. Therefore, it was found that no insoluble complex is formed between cholesterol and $\beta$-CD. In addition, the fluorescence intensities of the test solution prepared in the presence of $\alpha$-CD $\left(1.0 \times 10^{-2} \mathrm{M}\right)$ and $\gamma$-CD $\left(2.0 \times 10^{-2} \mathrm{M}\right)$ according to Solubility Method (2) were consistent with those of respective control solutions due to $\alpha-\mathrm{CD}$ and $\gamma-\mathrm{CD}$, Therefore, no insoluble or soluble complexes are formed between cholesterol and the three CDs under the present experimental conditions.

Since soluble complex formation between cholesterol and DOM- $\beta$-CD is strongly suggested, the interaction between them was investigated by making a phase solubility diagram, according to Solubility Method (2). The results are shown in Fig. 2. Phase solubility diagram of cholesterol with DOM- $\beta$ $\mathrm{CD}$ is of the Ap type. Therefore, it is presumed that cholesterol forms two types of complex with DOM- $\beta-\mathrm{CD}$, having molar ratios of $1: 1$ and $1: 2$, respectively, in aqueous solution.

The formation constants $K_{1: 1}$ and $K_{1: 2}$ defined by following Eqs. 3 and 4 were determined:

$$
\begin{aligned}
& \text { Cho+CD } \leftrightarrows \text { Cho-CD } \\
& \text { Cho-CD+CD } \leftrightarrows \text { Cho-CD } 2
\end{aligned}
$$

Table 1. Increase in Absorbance Due to Cholesterol Dissolved by CDs in Aqueous Solution at $37^{\circ} \mathrm{C}$

\begin{tabular}{ll}
\hline \hline \multicolumn{1}{c}{$\mathrm{CD}^{a)}$} & Absorbance $(600 \mathrm{~nm})$ \\
\hline Without CD & 0 \\
$\alpha$-CD & 0 \\
$\beta$-CD & 0 \\
$\gamma$-CD & 0 \\
HP- $\beta$-CD & 0.01 \\
DOM- $\beta$-CD & 0.336 \\
\hline
\end{tabular}

a) Concentration of CDs added is $1.0 \times 10^{-2} \mathrm{M}$.

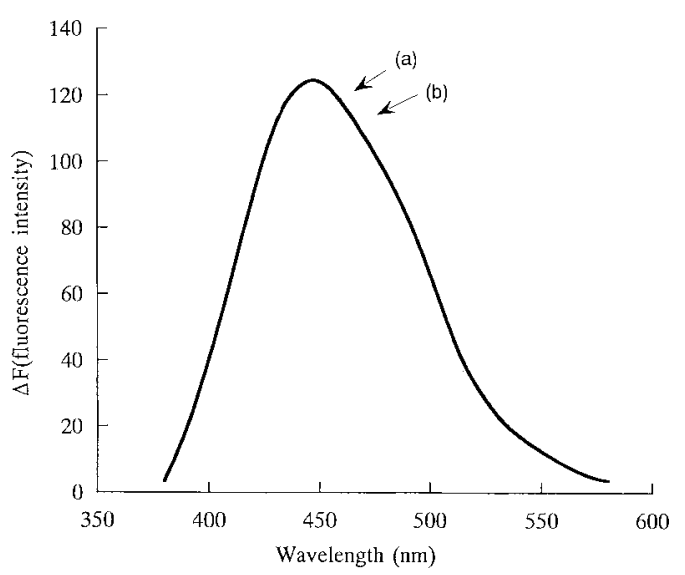

Fig. 1. Fluorescence Spectra of TNS $\left(1.0 \times 10^{-5} \mathrm{M}\right)$ in the Presence of $\beta$ $\mathrm{CD}$

(a) $\beta$-CD solution $\left(5.0 \times 10^{-3} \mathrm{M}\right)$ which is obtained after the solubility equilibrium with cholesterol. (b) $\beta$-CD control solution $\left(5.0 \times 10^{-3} \mathrm{M}\right)$.

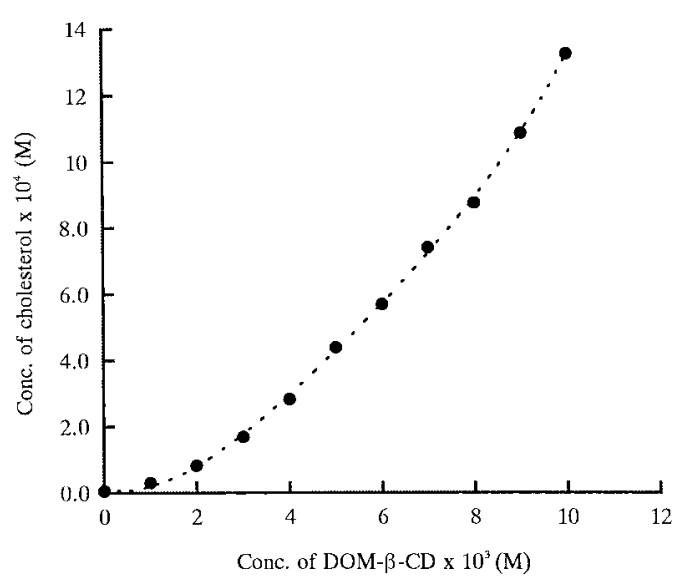

Fig. 2. Phase Solubility Diagram of Cholesterol with DOM- $\beta$-CD in Water at $37^{\circ} \mathrm{C}$

$$
\begin{aligned}
& K_{1: 1}=\frac{[\mathrm{Cho}-\mathrm{CD}]}{[\mathrm{Cho}][\mathrm{CD}]} \\
& K_{1: 2}=\frac{\left[\mathrm{Cho}-\mathrm{CD}_{2}\right]}{[\mathrm{Cho}-\mathrm{CD}][\mathrm{CD}]} \\
& {[\mathrm{Cho}]_{\mathrm{t}}=[\mathrm{Cho}]+[\mathrm{Cho}-\mathrm{CD}]+\left[\mathrm{Cho}-\mathrm{CD}_{2}\right]} \\
& {[\mathrm{CD}]_{\mathrm{t}}=[\mathrm{CD}]+[\mathrm{Cho}-\mathrm{CD}]+2\left[\mathrm{Cho}-\mathrm{CD}_{2}\right]}
\end{aligned}
$$

where [Cho] and [CD] are concentrations of free cholesterol and DOM- $\beta-\mathrm{CD}$, respectively, and [Cho-CD], and [Cho$\mathrm{CD}_{2}$ ] are concentrations of complexes with molar ratios of $1: 1$ and $1: 2$, respectively. [Cho $]_{\mathrm{t}}$ and $[\mathrm{CD}]_{\mathrm{t}}$ represent total 
concentrations of cholesterol and DOM- $\beta$-CD, respectively.

The combination of Eqs. 3, 4, 5, and 6 gave Eq. 7.

$$
\begin{aligned}
{[\mathrm{Cho}]_{\mathrm{t}} } & =\frac{4 K_{1: 1} K_{1: 2}[\mathrm{Cho}][\mathrm{CD}]_{\mathrm{t}}-K_{1 ; 1}^{2}[\mathrm{Cho}]^{2}+1}{8 K_{1: 1} K_{1: 2}[\mathrm{Cho}]} \\
- & \left\{8 K_{1: 1}^{3} K_{1: 2}[\mathrm{CD}]_{\mathrm{t}}[\mathrm{Cho}]^{3}+8 K_{1: 1} K_{1: 2}[\mathrm{Cho}][\mathrm{CD}]_{\mathrm{t}}+K_{1: 1}^{4}[\mathrm{Cho}]^{4}\right. \\
& \left.-2 K_{1: 1}^{2}[\mathrm{Cho}]^{2}+1-16 K_{1: 1}^{2} K_{1: 2}[\mathrm{Cho}]^{2}[\mathrm{Cho}]_{\mathrm{t}}\right\}^{1 / 2} /\left\{8 K_{1: 1} K_{1: 2}[\mathrm{Cho}]\right\}
\end{aligned}
$$

Then, it is necessary to know [Cho], the free concentration of cholesterol equal to the solubility of cholesterol in water. Although the solubility of cholesterol in water has been reported to be $4.7 \times 10^{-6} \mathrm{M}$ in water, ${ }^{8)}$ the experimental conditions including the temperature at which measurement was made are not clear in the report. Therefore, the solubility was determined in accordance with Solubility Method (1) described in the Experimental section, at four temperatures, as shown in Table 2. Formation constants $K_{1: 1}$ and $K_{1: 2}$ can be

Table 2. Solubility of Cholesterol in Warer

\begin{tabular}{cc}
\hline \hline Temperature $\left({ }^{\circ} \mathrm{C}\right)$ & Solubility $(\mathrm{M}) \times 10^{6}$ \\
\hline 10 & $2.6 \pm 0.2$ \\
25 & $3.4 \pm 0.3$ \\
37 & $4.5 \pm 0.4$ \\
45 & $5.7 \pm 0.5$ \\
\hline
\end{tabular}

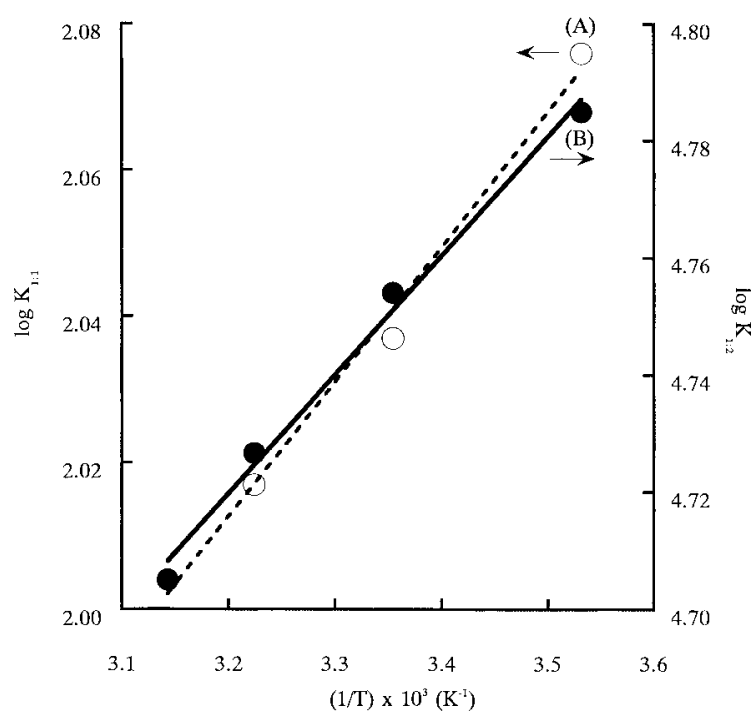

Fig. 3. The van't Hoff Plot of the Data in Table 3

(A): $\bigcirc$ for $K_{1: 1},(\mathrm{~B}): \bullet$ for $K_{1: 2}$. estimated from Eq. 7 using the nonlinear least-squares program MULTI. ${ }^{9)}$ The values obtained at $10,25,37$, and $45^{\circ} \mathrm{C}$ are shown in Table 3. Formation constant $K_{1: 1}$ of the $1: 1$ complex was $109 \mathrm{M}^{-1}$ and formation constant $K_{1: 2}$ of the $1: 2$ complex was $5.68 \times 10^{4} \mathrm{M}^{-1}$ at $25^{\circ} \mathrm{C}$, respectively.

It was found that complex with a molar ratio of $1: 2$ (cholesterol: $\mathrm{CD}$ ) is formed more easily than that of molar ratio of $1: 1$. The van't Hoff plots for the $1: 1$ and $1: 2$ complexes obtained by plotting $\log K$ against the reciprocal of the absolute temperature are shown in Fig. 3. The changes in enthalpy $\left(\Delta H^{\circ}\right)$ and the changes in entropy $\left(\Delta S^{\circ}\right)$ accompanying the complexation were determined from the slope and intercept, respectively, of the straight line obtained. Each value obtained is given in Table 3. The changes in enthalpy $\Delta H_{1: 1}^{\circ}$ of the $1: 1$ complex and $\Delta H_{1: 2}^{\circ}$ of the $1: 2$ complex were $-3.38 \mathrm{~kJ} / \mathrm{mol}$ and $-3.96 \mathrm{~kJ} / \mathrm{mol}$, respectively. On the other hand, the changes in entropy $\Delta S_{1: 1}^{\circ}$ and $\Delta S_{1: 2}^{\circ}$ were 27.7 $\mathrm{kJ} /(\mathrm{mol} \cdot \mathrm{K})$ and $77.6 \mathrm{~kJ} /(\mathrm{mol} \cdot \mathrm{K})$, respectively.

${ }^{1} \mathrm{H}-\mathrm{NMR}$ spectra and Corey-Pauling-Koltun (CPK) atomic models were used to estimate the structure of the $1: 2$ complex of cholesterol: DOM- $\beta$-CD. The molecular size and structure of the guest molecule and cavity of the host molecule can be estimated using CPK atomic models. In Fig. 4a, the ${ }^{1} \mathrm{H}-\mathrm{NMR}$ spectrum of $1.0 \times 10^{-2} \mathrm{M}$ DOM- $\beta$-CD in deuterium oxide at $25^{\circ} \mathrm{C}$ is shown. The assignments of the proton signals of DOM- $\beta$-CD have been reported previously. ${ }^{10)}$ In the presence of $1.2 \times 10^{-3} \mathrm{M}$ cholesterol, the proton signals of DOM- $\beta$-CD were observed. This sample was prepared in deuterium oxide in a manner based on Fig. 2. The proton signals shifted as shown in Fig. 4b. The values of changes in shift are shown in Fig. 5; the proton signal due to 3-H shifted upfield most prominently, followed by the signals due to $5-\mathrm{H}$, and 6-H. These protons lie on inner surface of the cavity of DOM- $\beta$-CD. The signals due to $1-\mathrm{H}$ and $4-\mathrm{H}$, which lie on the outer surface of the cavity, also shifted upfield. On the other hand, the proton signals due to the 6-OMe and 2-OMe groups, which lie at the entrances of the cavity of the primary hydroxyl group side and the secondary hydroxyl group side, respectively, shifted downfield. $2-\mathrm{H}$ on the outer surface of the secondary hydroxyl group side also shifted downfield. To confirm the structure of the $1: 2$ inclusion complex, the ROESY spectrum was measured (Fig. 6). In the ROESY spectrum of the solution containing cholesterol $\left(1.2 \times 10^{-3} \mathrm{M}\right)$ and DOM- $\beta$-CD $\left(1.0 \times 10^{-2} \mathrm{M}\right)$, cross peaks connecting the $3-$ $\mathrm{H}, 5-\mathrm{H}$, and $6-\mathrm{H}$ of DOM- $\beta-\mathrm{CD}$ to the $18-\mathrm{Me}, 26-\mathrm{Me}, 27-$ $\mathrm{Me}, 21-\mathrm{Me}$, and 19-Me of cholesterol were observed. The assignments of the proton signals of cholesterol in deuterium oxide were carried out with reference to those measured in

\begin{tabular}{|c|c|c|c|c|c|c|c|c|c|c|}
\hline \multirow{2}{*}{$\begin{array}{l}\text { Temp } \\
\left({ }^{\circ} \mathrm{C}\right)\end{array}$} & \multicolumn{2}{|c|}{$\begin{array}{c}K \\
\left(\mathrm{M}^{-1}\right)\end{array}$} & \multicolumn{2}{|c|}{$\begin{array}{c}\Delta G^{\circ} \\
\left(\mathrm{kJ} \cdot \mathrm{mol}^{-1}\right)\end{array}$} & \multicolumn{2}{|c|}{$\begin{array}{c}\Delta H^{\circ} \\
\left(\mathrm{kJ} \cdot \mathrm{mol}^{-1}\right)\end{array}$} & \multicolumn{2}{|c|}{$\begin{array}{c}\Delta S^{\circ} \\
\left(\mathrm{J} \cdot \mathrm{mol}^{-1} \mathrm{~K}^{-1}\right)\end{array}$} & \multicolumn{2}{|c|}{$\begin{array}{c}T \Delta S^{\circ} \\
\left(\mathrm{kJ} \cdot \mathrm{mol}^{-1}\right)\end{array}$} \\
\hline & $K_{1: 1}$ & $K_{1: 2}$ & $\Delta G_{1: 1}^{\circ}$ & $\Delta G_{1: 2}^{\circ}$ & $\Delta H_{1: 1}^{\circ}$ & $\Delta H_{1: 2}^{\circ}$ & $\Delta S_{1: 1}^{\circ}$ & $\Delta S_{1: 2}^{\circ}$ & $T \Delta S_{1: 1}^{\circ}$ & $T \Delta S_{1: 2}^{\circ}$ \\
\hline 10 & 119 & 61000 & -11.3 & -25.9 & & & $27.8 \pm 2.2$ & $77.6 \pm 6.2$ & 7.87 & 22.0 \\
\hline 25 & 109 & 56800 & -11.6 & -27.1 & $-3.38 \pm 0.27$ & $-3.96 \pm 0.32$ & $27.7 \pm 2.2$ & $77.7 \pm 6.2$ & 8.26 & 23.2 \\
\hline 37 & 104 & 53300 & -11.9 & -28.1 & & & $27.7 \pm 2.2$ & $77.7 \pm 6.2$ & 8.59 & 24.1 \\
\hline 45 & 101 & 50700 & -12.2 & -28.7 & & & $27.7 \pm 2.5$ & $77.6 \pm 6.2$ & 8.81 & 24.7 \\
\hline
\end{tabular}
$\mathrm{CDCl}_{3} \cdot{ }^{11}$

Table 3. Thermodynamic Parameters for Inclusion Complex Formation of Cholesterol with DOM- $\beta-\mathrm{CD}^{a}$ )

a) Formation constant $\left(K_{1: 1}, K_{1: 2}\right)$; average probable errors $\pm 7 \%$. 


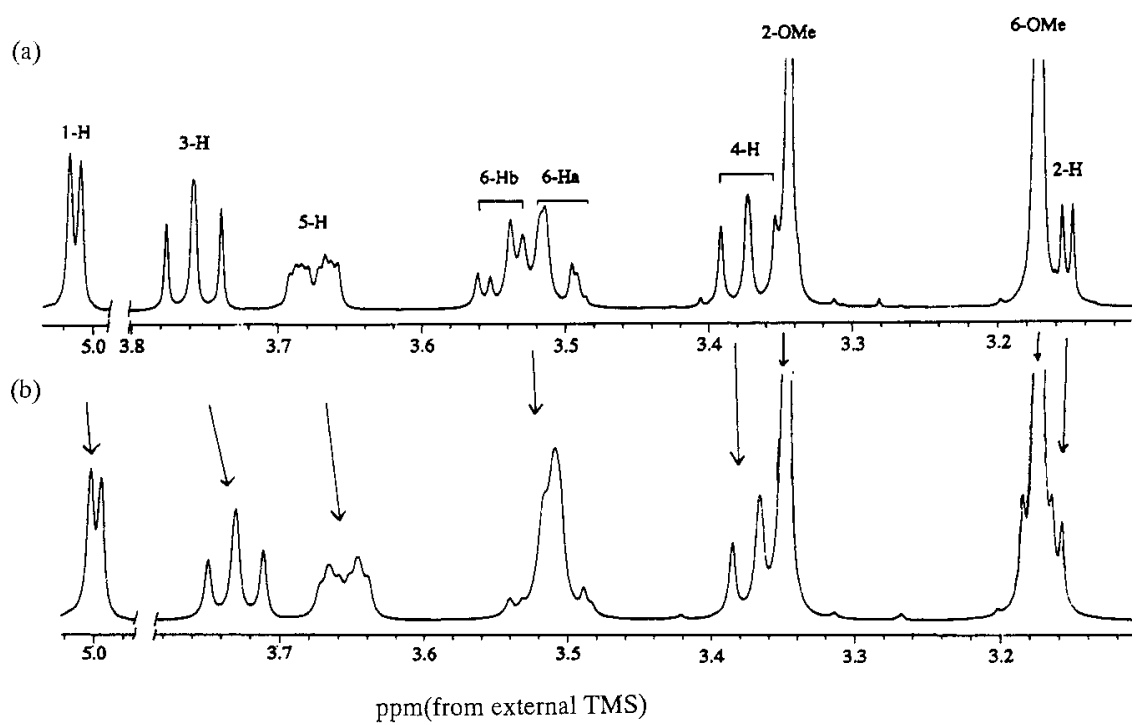

Fig. 4. ${ }^{1} \mathrm{H}-\mathrm{NMR}$ Spectra of DOM- $\beta$-CD in the Presence of Cholesterol in Deuterium Oxide at $25^{\circ} \mathrm{C}$

(a) DOM- $\beta$-CD alone $\left(1.0 \times 10^{-2} \mathrm{M}\right)$, (b) DOM- $\beta$-CD $\left(1.0 \times 10^{-2} \mathrm{M}\right)+$ cholesterol $\left(1.2 \times 10^{-3} \mathrm{M}\right)$.
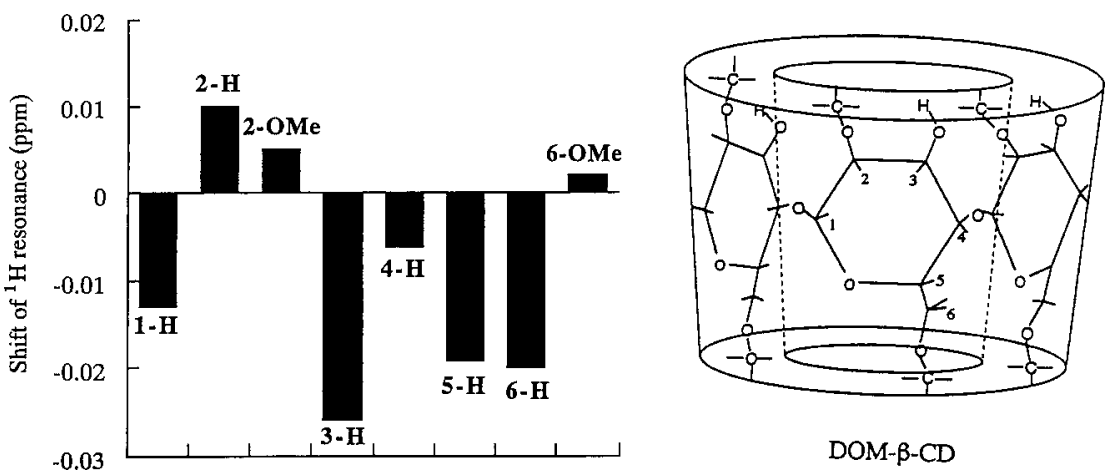

Fig. 5. Induced ${ }^{1} \mathrm{H}-\mathrm{NMR}$ Chemical Shifts of DOM- $\beta$-CD $\left(1.0 \times 10^{-2} \mathrm{M}\right)$ in the Presence of Cholesterol $\left(1.2 \times 10^{-3} \mathrm{M}\right)$ in Deuterium Oxide at $25^{\circ} \mathrm{C}$

\section{Discussion}

From the results of ${ }^{1} \mathrm{H}-\mathrm{NMR}$ spectra and the investigation using CPK atomic models, three possible structures for the inclusion complex of cholesterol with DOM- $\beta$-CD (cholesterol: $\mathrm{DOM}-\beta-\mathrm{CD}=1: 2)$ were estimated, as shown in Fig. 7. The structure in which two DOM- $\beta$-CD molecules include cholesterol from the side of the primary hydroxyl group of the $\mathrm{CD}$ was omitted because it is difficult for the hydroxyl group portion of cholesterol to pass through the cavity of the primary hydroxyl group side of the DOM- $\beta$-CD, as based on the examination using CPK atomic models. At (a), (b), and (c) in Fig. 7, it is assumed that the upfield shifts of $3-\mathrm{H}, 5-\mathrm{H}$, and $6-\mathrm{H}$ of DOM- $\beta-\mathrm{CD}$ are induced by both the magnetic anisotropy effect due to the double bond of cholesterol at 5 position and the changes in magnetic environment due to invasion of the hydrophobic group. ${ }^{12,13)}$ Also, it is considered that the downfield shifts of 2-OMe and 6-OMe occur because 2-OMe comes into contact with another 2-OMe (a) or 6OMe comes into contact with $2-\mathrm{OMe}(\mathrm{b})$ or (c), that is, by the steric compression effect. It is assumed that $2-\mathrm{H}$ shifted downfield due to the steric compression effect because the contact of 2-OMe with another 2-OMe induces a conformation change in $2-\mathrm{OMe}$, with the result that $2-\mathrm{H}$ comes into contact with 2-OMe.The cross peaks connecting the $3-\mathrm{H}$ of
DOM- $\beta$-CD to the four types of proton of cholesterol (18$\mathrm{Me}$, 26-Me[27Me], 21-Me, and 19-Me) are explicable mainly by Figs. 7 (a), (b), (a), and (c), respectively. The cross peaks connecting the $5-\mathrm{H}$ of DOM- $\beta$-CD to connecting to the four kinds of proton of cholesterol mentioned above are explicable by Figs. 7 (c), both (a) and (c), (b), and both (a) and (c), respectively. In the same way, the cross peaks connecting the 6-H of DOM- $\beta$-CD to the four types of proton of cholesterol are explicable by Figs. 7 (c), (c), (b), and both (b) and (a), respectively.

It was found that DOM- $\beta$-CD forms a $1: 2$ complex $(\mathrm{DOM}-\beta-\mathrm{CD}$ : cholesterol $=1: 2$ ) with cholesterol more easily than $1: 1$ complex. In addition, it was found that $1: 2$ and $1: 1$ complex formations were accompanied by a negative change in enthalpy and positive change in entropy, and therefore the enthalpy term and entropy term both contribute complex formation. From the thermodynamic parameters shown in Table 2 for the formation of $1: 2$ complex at $25^{\circ} \mathrm{C}$, the entropy term $\left(T \Delta S_{1: 2}^{\circ}=23.2 \mathrm{~kJ} / \mathrm{mol}\right)$ contributes much more to the standard Gibbs free energy change $\left(\Delta G_{1: 2}^{\circ}=-27.1\right.$ $\mathrm{kJ} / \mathrm{mol})$ than that of the enthalpy term $\left(\Delta H_{1 \cdot 2}^{\circ}=-3.96\right.$ $\mathrm{kJ} / \mathrm{mol}$ ). The contribution of the entropy term was about $86 \%$. Based on these results, it becomes apparent that the main driving force for $1: 2$ complex formation is hydropho- 


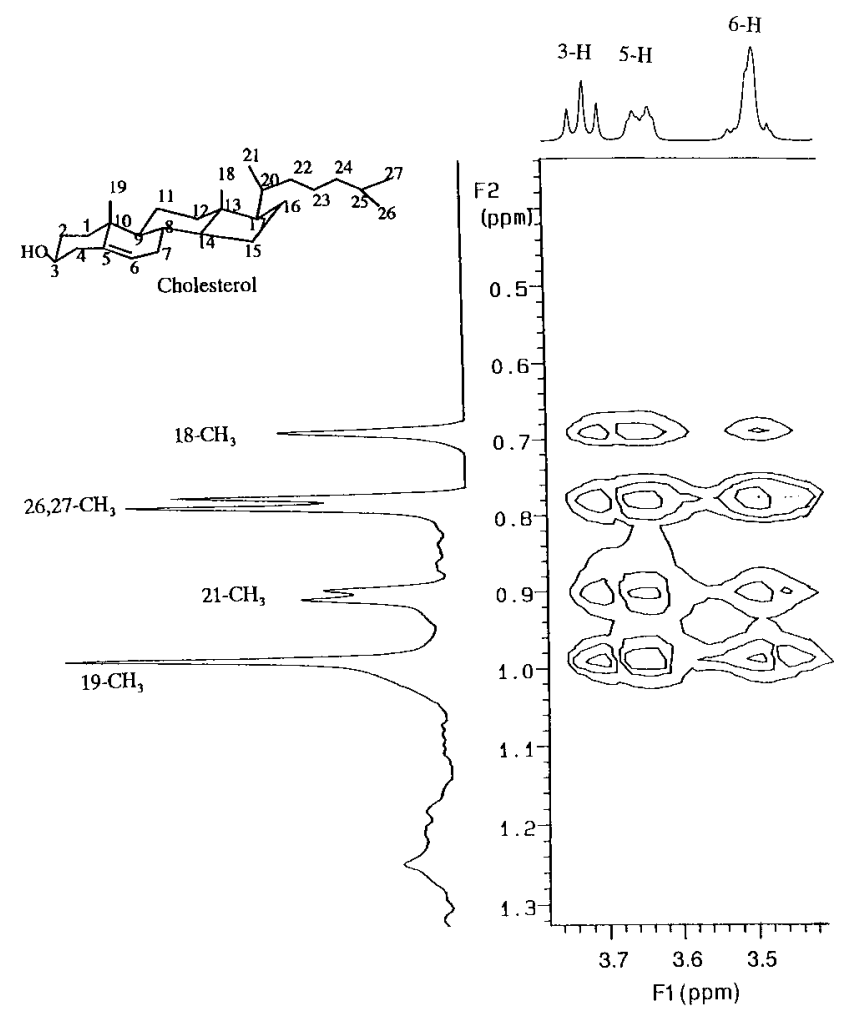

Fig. 6. ROESY Spectrum of Solution Containing DOM- $\beta$-CD $\left(1.0 \times 10^{-2} \mathrm{M}\right)+$ and Cholesterol $\left(1.2 \times 10^{-3} \mathrm{M}\right)$

bic interaction, as expected. Also, for $1: 1$ complex formation at $25^{\circ} \mathrm{C}$, the entropy term $\left(T \Delta S_{1: 1}^{\circ}=8.26 \mathrm{~kJ} / \mathrm{mol}\right)$ contributes more to standard Gibbs free energy change $\left(\Delta G_{1: 1}^{\circ}=-11.6 \mathrm{~kJ} / \mathrm{mol}\right)$ than does the enthalpy term $\left(\Delta H_{1: 1}^{\circ}=-3.38 \mathrm{~kJ} / \mathrm{mol}\right)$. The contribution of the entropy term was $71 \%$. The main driving force for $1: 1$ complex formation was found to be hydrophobic interaction, although the rate of contribution of the entropy term is less than that for $1: 2$ complex formation.

DOM- $\beta$-CD has a chemical structure in which two-thirds of the hydroxyl groups of $\beta$-CD are methylated. Therefore, it has a deeper cavity and is more hydrophobic than other CDs. This might enable DOM- $\beta$-CD to form inclusion complexes with the much more hydrophobic compound cholesterol by hydorophobic interaction. When the $1: 1$ complex structure was examined using the CPK atomic model, it was found that about one-half of the hydrophobic cholesterol molecule projects into the aqueous solution. Thus, the water molecule around the projected moiety of cholesterol molecule might form an iceberg structure, resulting in a decrease in entropy. It is estimated that the difficulty of $1: 1$ complex formation is due to this thermodynamic lability. On the other hand, in the $1: 2$ complex, the entire cholesterol molecule is included in the cavity of DOM- $\beta$-CD and the hydrophobic moiety of cholesterol projects very little into the aqueous solution. In addition, two DOM- $\beta$-CD molecules are in contact with each other, as shown in Fig. 5. These phenomena result in the water molecules of iceberg structure around both cholesterol and DOM- $\beta-\mathrm{CD}$ becoming free water molecules, with a large increase in entropy. As a result, it is estimated that the formation constant $\left(K_{1: 2}\right)$ for the $1: 2$ complex becomes far (a)

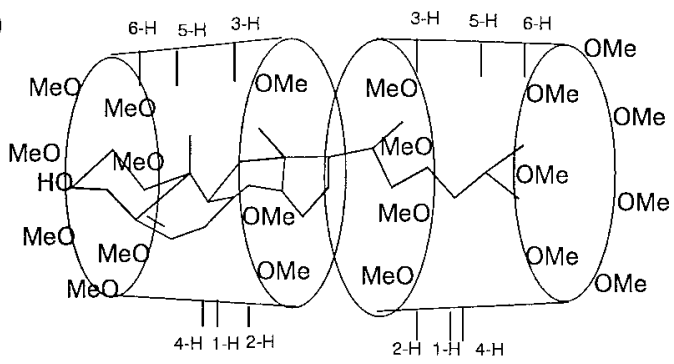

(b)

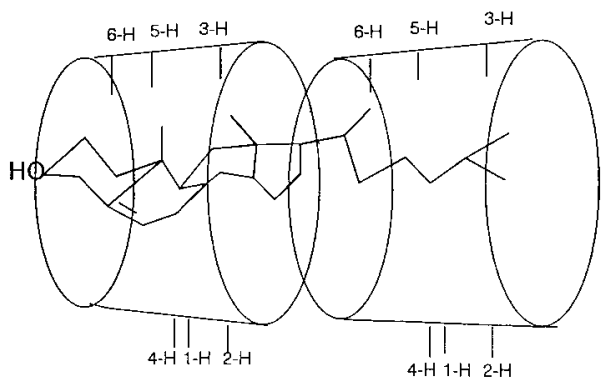

(c)

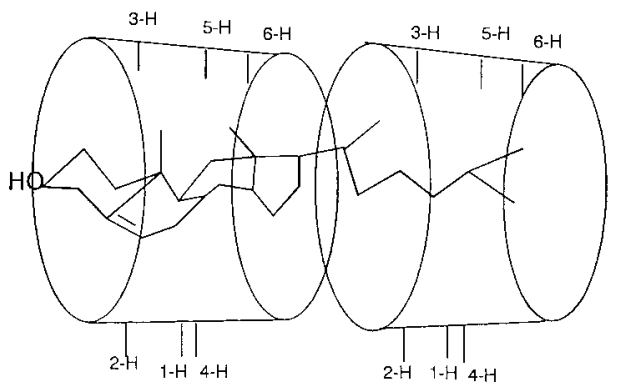

Fig. 7. Possible Structures of the $1: 2$ Complex of Cholesterol with DOM$\beta$-CD

Some of -OMe groups (a) and all of them (b and c) are deleted for easier understanding of the figure.

larger than that of the $1: 1$ complex $\left(K_{1: 1}\right)$.

Acknowledgements We are grateful to Dr. Makiko Sugiura for her measurements of ${ }^{1} \mathrm{H}-\mathrm{NMR}$ spectra.

\section{References}

1) Craven B. M., Nature (London), 260, 727-729 (1976).

2) Maulik P. R., Shipley G. G., Biochemistry, 35, 8025-8034 (1996).

3) Frijlink H. W., Eissens A. C., Helfting N. R., Poelstra K., Lerk C. F., Meijer D. K. F., Pharm. Res., 8, 9-16 (1991).

4) Henna O., Slott J. P., Biochemistry, 35, 8018-8024 (1996).

5) Kilsdonk E. P. C., Yancey P. G., Stoudt G. W., Bongertert F. W., Johnson W. J., Phillips M. C., Rothblat G. H., J. Bio. Chem., 270, 1725017256 (1995).

6) Nishijo J., Yasuda M., Nagai M., Ohno E., Chem. Pharm. Bull., 40, $2591-2596$ (1992).

7) Nishijo J., Nagai M., Yasuda M., Ohno E., Ushiroda Y., J. Pharm. Sci., 84, 1420-1426 (1995).

8) Haberland M. E., Reynolds J. A., Proc. Natl. Acad. Sci. U.S.A., 70, 2313-2316 (1973).

9) Yamaoka K., Nakagawa T., J. Pharmacobio-Dyn., 6, 595-600 (1983).

10) Nishijo J., Nagai M., Yasuda M., Carbohydr. Res., 245, 43-45 (1993).

11) Ravichandran R., Vivakar S., J. Incl. Phenom., 30, 253-270 (1998).

12) Meijer M. M., Luiz M. T. B., Farmer P. J., Szpoganicz B., J. Incl. Phenom. Macrocycl. Chem., 40, 291-295 (2001).

13) Schneider H.-J., Hacket F., Rüdiger V., Ikeda H., Chem. Rev., 98, 1755-1785 (1998). 